\title{
Developing Markets for Recycled Organic Products in Florida ${ }^{1}$
}

\author{
Mohammad Rahmani, Alan W. Hodges, and Clyde F. Kiker²
}

\section{Introduction}

Issues on various aspects of recycled organic products are drawing increasing attention from public and private sectors. However, most of the attention is being paid to organic recycling as a potential means of reducing wastes going to landfills. It is obvious that conversion of organic solid wastes to various products will reduce disposal problems. Organic solid wastes include municipal solid wastes, yard debris, wood wastes, animal related wastes, and food wastes (from restaurants). Markets with continuous demand need to be developed for these products to be moved out of recycling facilities so they can beneficially be used. In order to promote using recycled organic products, these products must bring additional value when used as soil amendments. While recycling organic materials may alleviate some of the landfill problems facing communities, it also could present problems for recycling facilities if they cannot profitably market recycled organic products.

Addressing the factors to develop recycled organic product markets may help recycling facilities enhance product output. Market surveys indicate that the major factors affecting the recycled organic product market in Florida are quality, information, and availability. Therefore, information on type and quantity of available recycled organic products, as well as on uses, locations, and outlets, is important for developing a relevant market.

Expanding on the results of recent studies, this document explores existing and potential recycled organic product markets in Florida - a real issue and challenge facing the organic recycling industry. In addition, this document utilizes data and information collected from two previous surveys on various aspects of recycled organic product demand and supply in Florida (Rahmani, et al., 2002, 2003). On the demand side, data were collected on issues such as problems experienced by compost users, sources of information about compost, barriers to using compost, and incentives for potential compost users. The surveys also explored issues of concern and the attitudes of both compost and non-compost users in Florida. The survey of organic recycling facilities in Florida addressed issues relevant to supply, including customers, capacity and actual volume and type of recycled organic products, percentage of products shipped, and shipping distance. Producers' marketing efforts, demand improvement initiatives, and customers' concerns were addressed in the survey.

1. This is EDIS document FE499, a publication of the Department of Food and Resource Economics, Florida Cooperative Extension Service, Institute of Food and Agricultural Sciences, University of Florida, Gainesville, FL. Published December 2004. Please visit the EDIS website at http://edis.ifas.ufl.edu.

2. Mohammad Rahmani, Coordinator of Economic Analysis; Alan W. Hodges, Associate In; and Clyde F. Kiker, Professor, Department of Food and Resource Economics, Florida Cooperative Extension Service, Institute of Food and Agricultural Sciences, University of Florida, Gainesville, FL. 


\section{Issues Relevant to Supply}

The number of facilities actively involved in some type of processing organic waste in Florida is estimated at about 90 facilities, based on responses from $34 \%$ of the surveyed facilities (Rahmani, 2003). The first inference from this study is that compost is typically not the number one product of organic recycling facilities in Florida. Survey data show that compost production is less than half that of mulch production. The survey also found that these facilities operate at considerably less that full capacity (estimation is $70 \%$ ) due to quality control, market oversupply, distance from potential users, and lack of information by potential users. Only $20 \%$ of the producers ship out all their products while $30 \%$ keep more than half of what they produce in their facilities. Producers with unsold products must reduce production, resort to free giveaways, or expand their lots.

\section{Volume and Type of Products}

There are three major types of products produced by organic recycling facilities in Florida: mulch, compost, and soil amendments. For all firms, mulch comprises $66 \%$, compost $27 \%$, and soil amendments $7 \%$ of total respondents' products. Some facilities produce more than one type of product.

\section{Type of Feedstocks}

Yard wastes, wood wastes, municipal solid wastes, and animal related wastes are the major types of feedstock used by the responding organic recycling facilities in Florida. Organic recycling facilities also use other types of materials, including landscaping and construction debris, food wastes, and bio-solids (dry sewage sludge). Figure 1 illustrates types of feedstocks used by respondents. For example, $84 \%$ of the respondents used yard debris and $48 \%$ of the respondents used wood wastes.

\section{Capacity Utilization}

Only $29 \%$ of the respondents use full capacity for converting wastes to other products, and total products represent about $70 \%$ of industry capacity. Labor and feedstock shortages, permitting problems, lack of capital, space limitations, and overstocked

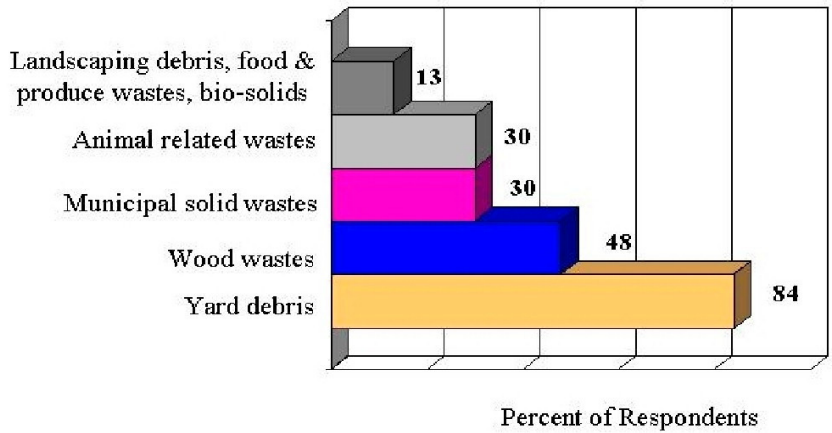

Figure 1. Type of feedstock used by responding organic recycling facilities in Florida (multiple responses).

finished products are listed among the reasons for not operating at full capacity.

\section{Customers}

Customers play a major role in establishing a recycled organic product market. Survey respondents list landscapers (74\%) and residential households (74\%) as constituting the major recycled organic product customers. Ornamental growers and crop growers constitute $16 \%$ and $10 \%$, respectively, of recycled organic product customers. Mulch production equaled $66 \%$ of the recycled organic products used for landscaping, which explains why residential customers and landscapers are the major users. Compost volume, used mainly by crop and ornamental growers, equals less than $50 \%$ of mulch volume. Other customers included counties, municipalities, and governments, which used recylced organic products for roadsides. Only one customer used recycled organic products as a fuel source.

\section{Products Shipped Out of Facilities}

Only $20 \%$ of respondents sell all of what they produce, and $30 \%$ sold less than half of what they produce. To prevent overstocking, some facilities give away part of their production for free, with about $41 \%$ of respondents giving away more than half of their products for free. More than $70 \%$ of the respondents accumulate unsold products at their sites indefinitely, and $13 \%$ deliver unsold products to other sites at their own expense.

\section{Shipping Distance}

The average distance for shipping products is less than 50 miles, with $48 \%$ of respondents shipping 
products within 20 miles of their facilities and $41 \%$ shipping between 20 to 50 miles. This information supports the thought that, from an economic point of view, compost cannot be delivered to locations more than 50 miles from production facilities. However, one respondent mentions that his product is shipped as far as 100 miles from the facility. Table 1 illustrates shipping distances as reported by organic recycling facilities in Florida.

Table 1. Shipping distances, by organic recycling facilities in Florida

\begin{tabular}{|cc|}
\hline \hline $\begin{array}{c}\text { Distance from } \\
\text { Recycling Facility }\end{array}$ & $\begin{array}{c}\text { Percent of } \\
\text { Respondents }\end{array}$ \\
\hline Up to 20 Miles & $48 \%$ \\
21 to 50 Miles & $41 \%$ \\
51 to 100 Miles & $8 \%$ \\
More Than 100 Miles & $3 \%$ \\
\hline Source: Survey & \\
\hline \hline
\end{tabular}

\section{Marketing Efforts}

Only one respondent uses a marketing firm to promote his products. Most respondents use public media ( $42 \%$ use local newspaper and television advertisements and 39\% use brochures) to promote their products. Also, $32 \%$ use solicitation by personal representatives to promote their products (Figure 2).

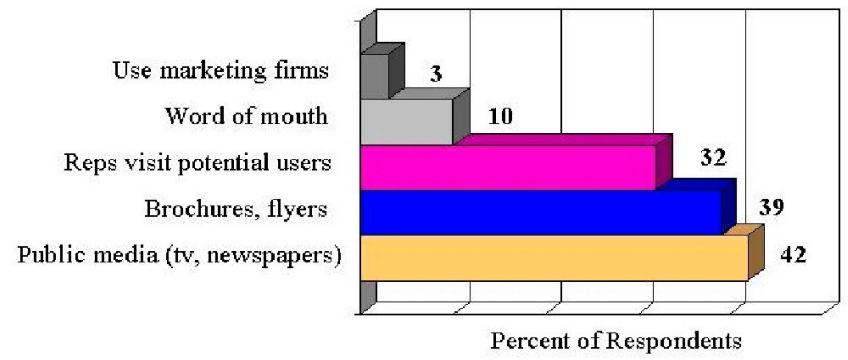

Figure 2. Marketing efforts by responding organic recycling facilities in Florida (multiple responses).

\section{Challenges in Selling the Products}

About $60 \%$ of the respondents attribute problems with selling their products to lack of proper quality - the primary issue that challenges organic recycling facilities products. Other reasons that hinder sales include distance from potential users (24\%), lack of information about product (12\%), and price of product (4\%). Around 19\% of the respondents do not have any problem selling their products (Figure 3).

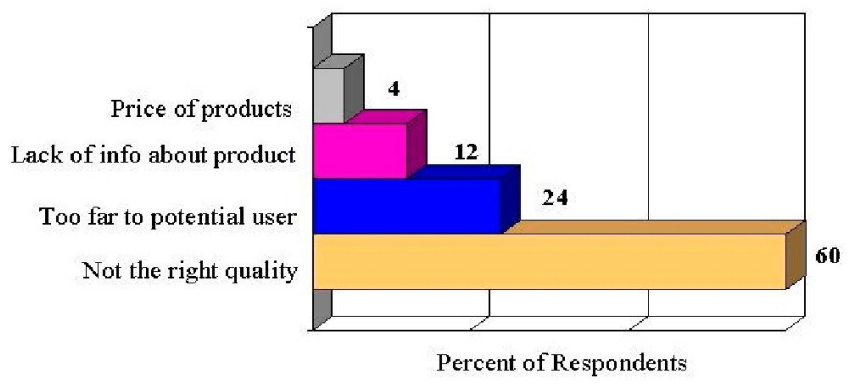

Figure 3. Reasons attributed by respondents for having difficulty selling products (multiple reasons).

\section{Issues Relevant to Demand}

A randomly selected telephone survey of user groups, including 248 citrus groves, golf courses, landscaping firms, and nurseries, from a total of 2,350 firms was performed to document factors affecting the demand for recycled organic products. The survey included various operation sizes as well as users and nonusers of compost. Results are based on percentage of respondents on each issue, some with multiple response options (Rahmani, et al., 2002).

\section{Recent Changes in Demand}

Respondents were asked to give their points of view concerning recent changes in compost and recycled organic product demand. Overall, $45 \%$ of the respondents believe there is no change in demand. However, $23 \%$ of the respondents report demand improvement within the past couple of years, resulting mainly from quality improvement as well as providing more information about their products.

\section{Improving Demand}

Producers' opinions were sought on improving recycled organic product demand, with 39\% indicating they do not think any action is needed to improve demand. The majority, however, consider improved product quality, transportation delivery, more information, and lower prices as major factors for demand improvement (Figure 4). Marketing effort was listed by $19 \%$ of respondents as a factor for demand improvement. 


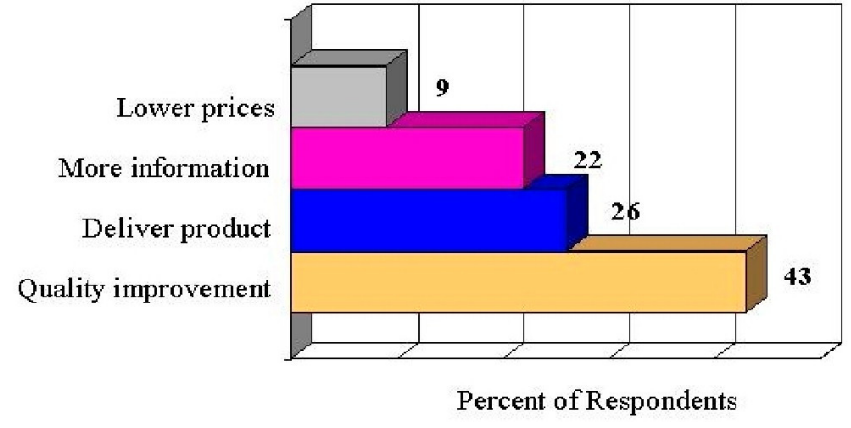

Figure 4. Respondents' views on improving demand (multiple responses).

\section{Quantity of Compost Used}

Total quantity of compost use is less than 10 tons annually for $38 \%$ of all respondents. Those who use 11 to100 tons of compost account for $40 \%$, and those using more than 100 tons account for only $8 \%$ of respondents. Data for each group show little difference for quantity of compost usage, and overall this information indicates that compost is not widely applied. No respondent in the landscaping group mentioned using more than 10 tons of compost per year. Data on application rate per acre indicate that compost application is not yet a common practice for agricultural crops. Half of the respondents used only 1 ton per acre of compost annually. Responses to this question were very low among compost users. Only $26 \%$ of compost users responded to this question, which could indicate some uncertainty about its use.

\section{Distance of Principal Supplier}

Except for the particular type(s) of compost used by nurseries or golf courses, which come from longer distances, $64 \%$ of compost use is hauled less than 30 miles. Only $25 \%$ of the respondents report getting compost from distances of 50 miles or more.

Compost transportation cost, which is very dependent upon distance, is one of the major issues of compost acceptance. Consistent availability of compost within an economically feasible distance is important for development of compost markets.

\section{Concerns to Compost Users}

Quality inconsistencies such as immature compost, weed seeds, and odor are the most important problems that respondents experience. Some respondents also mention price (13\%) and consistent availability of compost $(10 \%)$ as problems they have experienced. Only $8 \%$ of the respondents indicate they do not have any problem using compost (Figure 5). Data for each group separately also indicate quality inconsistency as the most important problem they experience. Citrus growers experience more problems with compost availability and application issues than other businesses. Landscaping services experience only quality inconsistency; however, only a few responded to this question. Problems such as immature compost, weed seed in compost, and odors may affect widespread application of compost by agricultural producers. Interestingly, 39\% of the organic recycling facilities that responded to our survey believe quality is customers' first concern, followed by issues of transportation and lack of information.

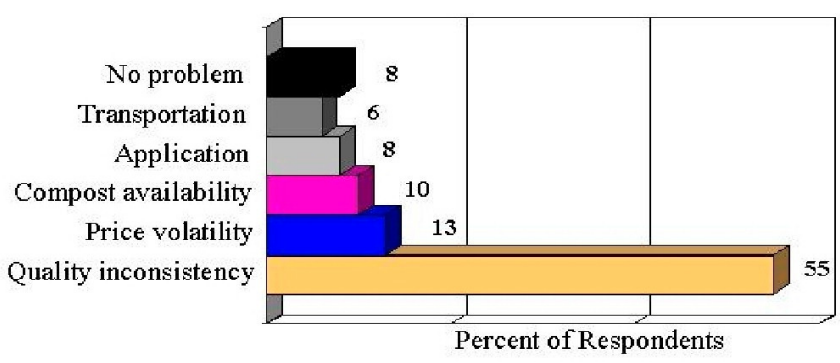

Figure 5. Concerns of compost users (multiple responses).

\section{Sources of Information about Compost}

Both compost users and producers believe that information is a major element for improving compost usage. One survey objective was to identify sources that provide information about compost. Industry cooperatives or associations or other operations in the area account for $22 \%$, and the Florida Cooperative Extension Service accounts for $20 \%$ of respondents' sources of information. Various trade magazines and publications play an important part in providing information about compost (18\%). University research centers are mentioned more often by compost users (17\%) than by non-compost users (5\%) as sources of information about compost. Compost marketing representatives also seem to have a role in introducing compost to farmers and growers. Apparently, non-compost users obtain information from sources other than those available to compost users. 
As a source of information, compost marketing representatives are quoted twice as often by compost users. Data for each business group show they all select the first four options illustrated in Figure 6 as the most important source of information.

Differences are noticed in ranking the importance of these four sources. Citrus growers and nurseries mention compost marketing representatives as the most important, golf courses mention industry cooperatives or associations as number one, and the Florida Cooperative Extension Service is the top source of information for landscaping respondents.

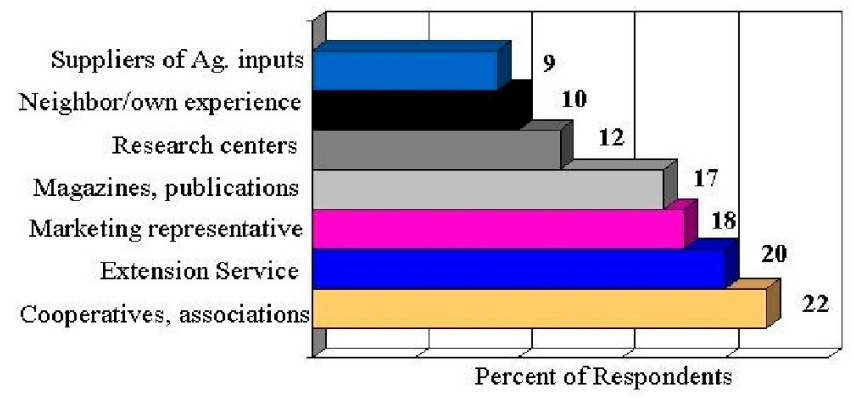

Figure 6. Sources of information about compost (multiple responses).

\section{Main Barriers to Using Compost}

Quality concerns seen as the most important problem for compost users are also considered to be the main barrier to expanding the compost market. Quality of compost and adverse reactions due to weed seed are mentioned as the main barriers by $45 \%$ of the respondents. Figure 7 illustrates other barriers indicated by respondents. Only $7 \%$ of the respondents believe there are no barriers to using compost. There are some interesting points noticed when responses by compost users are compared with non-compost users. Compost users mention price as the second most important barrier, whereas non-compost users rank this option as the least important one (18\% versus $10 \%)$. Adverse reaction to herbicide or pesticide residues is the least important barrier from the compost users' point of view, whereas non-compost users ranked this option as the second most important barrier. Other options are ranked the same by both user and non-user groups. Among business groups, except for citrus growers who indicate "quantity of compost needed is not available" as the most important barrier, other business groups rank the options consistent with results for all the respondents as illustrated in Figure 7.

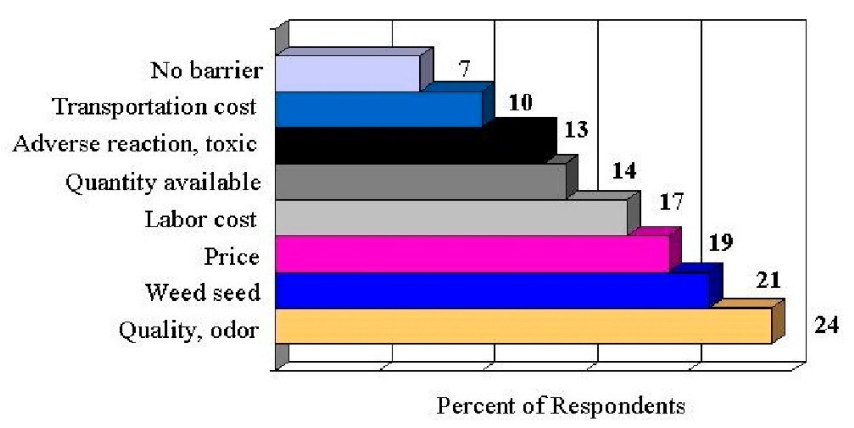

Figure 7. Main barriers to using compost (multiple responses).

\section{Encouraging Potential Users to Use Compost}

Only non-compost users were surveyed, so there is no comparison to compost users. As Figure 8 illustrates, information is the key to developing compost usage. Interestingly, three times more respondents indicate that more information would be an enticement (69\%) than those who mention delivery of no-cost compost (21\%). More than $25 \%$ of the respondents believe they need to be convinced that the benefit of compost exceeds the cost of its application. Only $7 \%$ of the respondents do not have any interest in using compost. There are no differences of opinion among various business groups in ranking issues of incentives.

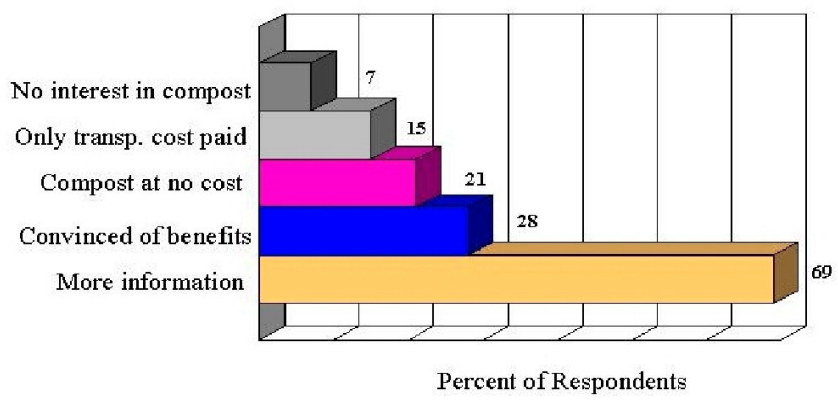

Figure 8. Incentives for greater compost use by potential compost users (multiple responses).

\section{Conclusions}

Organic recycling facilities can best increase use of their products through improving marketing and demand. The first inference from collected data is that in terms of quantity, compost is not the number one product of organic recycling facilities in Florida. 
Survey data show that compost production is less than half that of mulch production. Presently, these facilities produce far below their capacities-only $70 \%$. There are several reasons expressed by producers, including quality, flooded market, distance from potential users, and lack of information by potential users. While only $20 \%$ of producers sell all their products, $30 \%$ have to keep more than half of what they produce in their own facilities or pay to dispose of it.

Results from the demand issues study indicate that quality, information, and consistent availability are key to demand improvement and eventually market improvement. Looking at responses to the present survey regarding difficulty selling the products, point of view on demand improvement, and customer concerns, all point to quality, transportation and delivery (actual availability), and information. Information provided by responding organic recycling facilities calls for more marketing efforts for product promotion, quality improvements, and methods facilitating delivery to increase potential customers.

Presently, there is a market for mulch. Mulch is a product of organic recycling facilities that can be produced more easily and at a lower cost. It can be sold to customers located close to conversion facilities. Compost is a more costly and longer processed product, with a limited market so far. Potential compost users usually are not located close to conversion facilities, which translate to higher transportation costs. In addition, compost users want to know: How much is it going to cost to apply it? How and where they can get it? How can it benefit them? Is the quality of the compost consistent? and Does it create problems such as weeds, odor, or toxicity?

Price, transportation distance, costs, and benefits are all part of the information that potential compost users need to make rational decisions. More information needs to be disseminated and the quality of compost needs to be improved and kept consistent for compost to become a more widely used input in agriculture. To promote using compost, it should be considered a commodity with net benefits for users. Marketing tools would have an important impact on encouraging greater compost usage and eventually development of a market for compost.

Since the whole organic recycling business exists to solve communities' waste disposal problems, it is logical for municipalities, counties, and state governments to support the efforts of the organic recycling industry, particularly when it comes to dissemination of information to the public.

\section{Acknowledgments}

The cooperation of Recycle Florida Today, particularly the efforts by Mr. Jeff Rogers, the chairman, and Mr. Chris Snow of the Organic Committee of Florida Recycle Today are sincerely appreciated. Our appreciation also extends to citrus growers, golf course managers, landscaping services, nurseries, and organic recycling facilities authorities in Florida for responding to our surveys. Investigators thank the Center for Natural Resources at the University of Florida for financial support of the surveys. Constructive comments given by reviewers, Drs. Robert Degner, Aziz Shiralipour, and David Mulkey, are greatly appreciated.

\section{References}

Beeson, R.C., R. Fluck, D. Graetz, G. Kidder, M. Marshall, T. Obreza, G.H. Snyder, A. Shiralipour, and W.H. Smith. 1997. A Market Development Program for Composts in Florida. Final Report submitted to the Center for Solid and Hazardous Waste, Department of Environmental Protection, State of Florida. Center for Biomass Programs, University of Florida.

Curtis, C., G. Brenniman, and W. Hallenbeck. 1992. Cost Calculations at MSW Composting Sites. BioCycle 33(1):70-74.

Division of Waste Management. 2000. Solid Wastes Management in Florida. Bureau of Solid and Hazardous Waste, Florida Department of Environmental Protection, Tallahassee, FL.

Goldstein N., and M. Madtes. 2000. The State of Garbage in America. BioCycle 42(12):42-54. 
Mitchell, D. (editor). 1997. Compost Utilization by Department of Transportation in The United States. Researched and written for the Florida Department of Transportation, Department of Environmental Horticulture, Soil and Water Science Department, University of Florida, Gainesville, FL.

Rahmani M., A.W. Hodges, and C.F. Kiker. 1999. Analyzing Compost Economics. BioCycle 40(7):66-69.

Rahmani M., A.W. Hodges, and C.F. Kiker. 2002. Florida Survey Reveals Why — and Why Not-Compost Is Applied. BioCycle 43(5):54-56

Rahmani, M., C.F. Kiker, and A.W. Hodges. 2003. Factors Affecting Compost Markets in Florida. Proceedings of the 2003 Recycle Florida Today, Inc. Annual Conference and Exhibition, St. Petersburg Beach, FL (June 2-4).

Recycle Florida Today-RFT. 2000. Organic Recycling Facilities in Florida. Compiled by RFTDivision, Florida Department of Environmental Protection, Tallahassee, FL.

Renkow M., C. Safley, and J. Chaffin. 1993. A Cost Analysis of Municipal Yard Waste Composting. ARE Report No. 6. Department of Agricultural and Resource Economics, North Carolina State University, Raleigh, NC.

Smith, W.H. (editor). 1995. Compost Test Program For The Palm Beach Solid Waste Authority Project. Final Report, Contract No. 93-100. Palm Beach Solid Waste Authority, Palm Beach, FL (May). 